\title{
La imagen de Donald Trump en la dramaturgia hispanoamericana emergente de Nueva York
}

\section{Antonio César Morón ${ }^{1}$}

Resumen. El interés fundamental de este artículo es comprender cuáles son los aspectos de las políticas generadas desde la actual administración de gobierno en Estados Unidos que más están interesando a los dramaturgos hispanoamericanos residentes en Nueva York. El colectivo hispano ha sido uno de los más aludidos a través de los discursos de Donald Trump, en diferentes entrevistas y mítines políticos. El resultado de este estudio tiene un matiz transversal, puesto que se realiza a partir de textos y entrevistas con los distintos dramaturgos y otros agentes de la cultura. Este matiz transversal que se concreta en los textos literarios, revela un estado psicológico y social determinado que podría llegar a considerarse reflejo de toda esta comunidad en el momento actual.

Palabras clave: teatro hispanoamericano; Nueva York; Donald Trump; política; imagen.

\section{[en] The image of Donald Trump in the emerging Hispanic American dramaturgy of New York}

Abstract. The main interest of this article is to understand what are the aspects of the policies generated from the current government administration in the United States that are most interesting to the Hispanic American playwrights living in New York. The Hispanic collective has been one of the most mentioned through the speeches of Donald Trump, in different interviews and political rallies. The result of this study has a transverse nuance, since it is made from texts and interviews with different playwrights and other agents of hispanic culture. This transversal nuance that is specified in the literary texts reveals a determined psychological and social state that could be considered a reflection of this whole community at the present time.

Keywords: Hispanic American theater; New York; Donald Trump; politics; image.

Sumario: 1. Introducción: delimitación y desarrollo de líneas de interés fundamentales. 1.1. Primera línea: fobias. 1.2. Segunda línea: estado psíquico. 1.3. Tercera línea: tema de Puerto Rico. 2. Obras dramáticas del teatro hispano con Donald Trump de fondo. 2.1. ¡Los huevos o la revolución! 2.2. Golpes de agua 2. Temporada de huracanes: todavía quedan restos de humedad. 2.3. Lo que nos dejó el huracán. 2.4. Literal. 2.5. Cada vagón es un mundo. 2.6. Queens of the night. 2.7. Trans-Mission. 2.8. Busca-la-vida. 3. Conclusión.

Cómo citar: Morón, A.C. (2021) La imagen de Donald Trump en la dramaturgia hispanoamericana emergente de Nueva York, en Anales de Literatua Hispanoamericana 50, 295-306.

\section{Introducción: delimitación y desarrollo de líneas de interés fundamentales}

El ocho de noviembre del año 2016 gana las elecciones de USA el que ha sido quizás el aspirante más controvertido de toda su historia: Donald Trump ${ }^{2}$. Si de algo no cabe duda es de que el candidato, con su lenguaje polémico, directo, agresivo y completamente al margen de lo políticamente correcto y del establishment, no dejó indiferente a nadie, generando filias y fobias por igual, pero sobre todo, generando audiencia. Todos estos elementos unidos a su mensaje principal de campaña, el famoso MAGA (Make America Great Again) lograron construir un mensaje emocional muy simple, pero muy eficaz en sus

\footnotetext{
1 Universidad de Granada. España

E-mail: acemores@gmail.com

${ }^{2}$ Un informe publicado por The Hispanic Council en octubre de 2015 destaca dos claves fundamentales en cuanto al éxito del candidato: las redes sociales (con más de cuatro millones y medio de seguidores en Twitter, más de cuatro millones en Facebook y casi medio millón en Instagram) y el capital desorbitado que el presidente está dispuesto a gastar en su propia campaña: mil millones de dólares.
} 
votantes: la esperanza de volver a confiar y estar protegidos por el gobierno de su país. Las críticas hacia la gestión del actual presidente y su equipo de gobierno se han venido sucediendo desde el inicio mismo de su campaña y, por supuesto, a lo largo de sus hasta ahora dos años de mandato. Nos interesan fundamentalmente para la elaboración de este artículo las críticas procedentes de ámbito teatral y, de manera más concreta, del ámbito del teatro hispano en la ciudad de Nueva York ${ }^{3}$. Después de contactar con personalidades distintas y significativas del fenómeno de la dramaturgia hispana de la ciudad y enviarles vía email una misma entrevista ${ }^{4}$ en la que se advertía previamente de su anonimato, pude construir un imaginario común en torno al tema propuesto. La entrevista fue respondida formalmente por una dramaturga, cinco dramaturgos, un crítico y un productor. Así mismo hubo otras muchas charlas de carácter informal: unas porque los participantes propuestos no querían dejar ningún tipo de huella acerca de sus consideraciones; otras porque, sencillamente, los participantes propuestos no tenían tiempo para reunirse o rellenar la entrevista, de manera que las pocas conclusiones que pude extraer fueron en completamente informales, pero de relevancia para mis conclusiones, ya que en todo momento observaba una sintonía con respecto al tema. Así descubrí que existe un patrón de tres líneas fundamentales en cuanto a la impresión generada acerca de la administración Trump, a las que se suma una reacción compartida por todos los participantes en la entrevista.

\subsection{Primera línea: fobias}

Una primera idea que se nos hace evidente a través de las respuestas de los encuestados es la de cómo Trump fabrica un estereotipo general de lo hispano que enmarca dentro de una misma categoría a la que dota toda de matices negativos, sin tener en cuenta los diferentes grupos y/o nacionalidades. Relacionado directamente con este rechazo de lo hispano por parte del presidente, encontramos el que ha sido quizás su discurso más beligerante, el que ha mantenido contra la inmigración desde una constante xenofobia. Uno de los entrevistados se hacía eco de la utilización de la misma como "una de las herramientas institucionalizadas en

${ }^{3}$ Dentro de la Ciudad, muchas obras y espectáculos que no habían sido exclusivamente pensados para hacer una crítica al gobierno adquieren una nueva reinterpretación y relectura de sus significados. Incluso, ha llegado a ocurrir que una compañía al completo salga al escenario al final del espectáculo para hacer llegar un mensaje directo a televisiones y prensa, como sucedió en Hamilton: An American Musical, estrenado en febrero de 2016 en el Teatro Público de Nueva York y trasladado meses más tarde al circuito de Broadway. Fue, en efecto, en el teatro Richard Rotgers donde el actual vicepresidente de los EE.UU. tuvo que escuchar estas palabras dirigidas hacia su persona y hacia toda la administración actual de gobierno: "Vice President-elect Pence, we welcome you and we truly thank you for joining here us at "Hamilton: An American Musical". We really do. We, sir, we are the diverse America who are alarmed and anxious that your new administration will not protect us, our planet, our children, our parents, or defend us and uphold our inalienable rights, sir. But we truly hope this show has inspired you to uphold our American values and to work on behalf of all of us. All of us. Again we truly thank you for sharing this show, this wonderful American story told by a diverse group of men, women of different colors, creeds and orientations". El texto fue enunciado por Brandon Victor Dixon, uno de los actores de la obra. Hamilton es un musical basado en un libro del historiador Ron Chernow, que el dramaturgo, compositor y actor Lin-Manuel Miranda preparó para ser montado como musical. La historia versa acerca de uno de los padres de la Constitución americana. Un hecho mucho más contundente fue el ocurrido en el verano del año 2017, con el montaje estrenado en el tradicional Delacorte Theater del festival Shakespeare in the Park de Nueva York, en el que se programó Julio César. La carcajada, al mismo tiempo que el posicionamiento de unos y otros espectadores, comenzó el mismo día del estreno cuando, de manera sorpresiva e inmediata el público pudo reconocer cómo varios de los personajes protagonistas eran identificables con Trump, con su esposa Melania o con su cuñado Jared. El personaje de Trump, concretamente, iba caracterizado con una enorme corbata roja y un color de pelo entre amarillento y anaranjado, exactamente el mismo característico color de pelo del presidente. Ahora bien, en un momento determinado, cuando sucede el asesinato de Julio César - Trump dentro de la obra, el público del estreno quedó completamente en silencio porque estaban viendo en ese acto una simulación del asesinato del presidente de los Estados Unidos. Dos de las compañías más importantes que prestaban su apoyo tradicionalmente al festival, financiando el montaje de las obras, dejaron de prestarlo. Así desde Bank of America y Delta Airlines se lanzaron sendos comunicados en los que básicamente se centraban en señalar cómo los valores que se trabajaban en ese montaje no coincidían con los valores que representaban sus respectivas empresas. En esta misma línea, pero construido expresamente desde el mismo título para enfatizar la polémica, se planeó el espectáculo Donald Trump dies in the end, del dramaturgo neoyorquino Travis Ferguson. Durante el mismo, tal y como se anunciaba en el programa de mano de la página web que albergó su publicidad, estaba proyectado que apareciera toda la familia del presidente y que, al final de la obra y tal y como se indicó desde el mismo título, Donald Trump muriese, concretamente guillotinado, al estilo de lo que hizo el pueblo de la Revolución Francesa con la aristocracia. El espectáculo estaba programado en el Fringe Festival de Nueva York, concretamente en el Brick Theater en Williamsburg (Brooklyn), del 31 de octubre al 4 de noviembre de 2018. Finalmente el espectáculo no se llevó a cabo debido a que el teatro donde se iba a presentar decidió no aceptar la pieza por lo extremo de su planteamiento y, a partir de ahí, por temor a protestas o ataques.

${ }^{4}$ Ofrezco a continuación la entrevista enviada:

BLOQUE I - IMAGEN. ¿Cuál es, bajo tu punto de vista, la imagen que Donald Trump tiene acerca de la comunidad hispana de Nueva York? ¿Cuál es, bajo tu punto de vista, la imagen que la comunidad hispana de Nueva York tiene acerca de Donald Trump?

BLOQUE II - POLÍTICA CULTURAL. ¿Cómo crees que ha influido, desde el punto de vista de la política cultural, la llegada al poder de Donald Trump y la actual administración de gobierno en la escena teatral hispana de Nueva York?

BLOQUE III - PRODUCCIÓN Y CREACIÓN TEATRAL. ¿Cuáles son, a tu parecer, los temas relacionados con Donald Trump y la actual administración de gobierno que más impactan o interesan al público de la escena teatral hispana de Nueva York? ¿Consideras que son compartidos con el público de la escena no hispana? ¿Tienes conocimiento de obras o montajes de teatro hispano donde aparezca o se hable acerca de Donald Trump o de la actual administración de gobierno bajo su mandato?¿Podrías adjuntar datos (título, fecha y lugar de estreno, autoría, dirección, etc.)? ¿Tienes escrita alguna obra o planeado un estreno inmediato en el que vayas a participar como intérprete o en la dirección o en la producción, etc., en el que exista algún tipo de relación con Donald Trump o la actual administración de gobierno? 
la política norteamericana", lo que quiere decir que la xenofobia serviría como método para medrar y llegar al poder político, siendo imposible en la actual administración hacer méritos para estar cerca del presidente sin hacer alarde de este tipo de mirada. Las siguientes fobias que destacan los encuestados son la homofobia y la transfobia del presidente, lo que ha hecho poner en pie de guerra a todo el colectivo LGTBQ.

\subsection{Segunda línea: estado psíquico}

Convendría establecer dos consideraciones diferentes en el grupo de respuestas generadas en torno a esta línea: la primera de ellas sería la visión de Trump como un desequilibrado. La segunda surge como fruto de esta, y establece la visión de Trump como una amenaza, para desembocar en el sentimiento de miedo y ansiedad que el discurso del presidente genera en las propias vidas de algunos de los encuestados. En cuanto a la primera consideración, uno de los encuestados responde: "Donald Trump es para nosotros un fantoche afectado por algún desequilibrio mental". En otra entrevista se argumenta algo parecido con la siguiente afirmación: "Donald Trump funciona en el nivel más asombroso de enajenación que he presenciado en mi vida". Dentro de esta mirada grotesca, se incardina la visión del afán pícaro y ridículo del presidente por hacer cualquier cosa para poseer bienes materiales y dinero. En cuanto a la consideración segunda, algunos encuestados detectan cómo esa sensación no sucede exclusivamente con ellos, sino que se extiende a distintos colectivos estigmatizados del mismo modo por la actual administración: "Lo 'fuckin' odiamos. Lo detestamos", dice uno de ellos; mientras otro añade: "La ansiedad no tiene nacionalidad. Aparte de los ataques a la comunidad hispana hay otros grupos que son constantemente atacados", para citar a "la comunidad afroamericana, la mujer, grupos LGTBQ, comunidades con limitados recursos económicos, inmigrantes de origen árabe. La lista es grande y se hacen espacios liminales en los que se comparten inquietudes".

\subsection{Tercera línea: tema de Puerto Rico}

Hay dos consideraciones fundamentales dentro de esta línea. Una de ellas está directamente relacionada con la administración actual de gobierno, dado que se refiere a la gestión de una catástrofe como el huracán María, que azotó la isla a finales de septiembre de $2017^{5}$. La segunda consideración se podría concebir como una derivación de esta primera, aunque el problema que trata no es exclusivo del actual gobierno, sino que ha permanecido vivo desde la misma anexión de la isla como botín de guerra en 1898: me estoy refiriendo al saqueo de Puerto Rico por parte de los EE.UU., que, con la actual administración y especialmente tras el trato percibido a partir de la tragedia del huracán María, se ha reavivado.

Ante estas tres líneas se impone una reacción compartida: la necesidad de unión solidaria de los hispanos ante los ataques públicos de Trump. No quiere esto decir que antes de la actual administración no existiera una solidaridad o unión entre los distintos grupos hispanos; sino que las declaraciones continuadas del presidente han generado una exacerbación de la identidad, especialmente en las ciudades más grandes del país, donde su población es más numerosa y cuenta con mayores y mejores medios y representación política. Así, uno de los encuestados afirma que desde la llegada de Trump "la comunidad teatral hispana ha empezado a resaltar más su identidad o más bien reclamar ser vista en y por sus identidades culturales y raciales", para, de paso, acercarnos además a un concepto más inclusivo y bastante más novedoso que el tradicional de spanish, como es el de "latinX", en el que se ampliaría la identidad de lo hispano a lo latino y, a partir de ahí, se incluiría toda la actual perspectiva de género aplicada a este adjetivo.

\section{Obras dramáticas del teatro hispano con Donald Trump de fondo}

\section{1. ¡Los huevos o la revolución!}

Comedia satírica del dramaturgo puertorriqueño Gama Valle ${ }^{6}$. El argumento de la historia nos sitúa en un país indefinido, de carácter al parecer latino, pero en el que se ha establecido como elemento de prestigio el conocimiento del inglés. ¿Podríamos hablar de un hipotético Puerto Rico independizado de los EE.UU.? Al

\footnotetext{
${ }^{5}$ A lo largo del año 2018 ha habido innumerables manifestaciones contra Trump en las que se han reivindicado fundamentalmente transparencia por parte del gobierno acerca del número de muertos reales.

${ }^{6}$ Esta obra fue seleccionada dentro del Play Development Program de IATI (Instituto de Arte Teatral Internacional) del año 2017 y programada como lectura dramatizada en 2018 tanto en IATI como en LATEA (Latino Theater in Lower East Side).
} 
presidente de este ficticio país se le ha intentado agredir con un huevo, hecho que lo lleva a la locura onírica, sufriendo pesadillas con el huevo agresor que le habla y le acosa; esa locura es trasladada a la realidad desde el poder de su mandato, impidiendo al pueblo tener huevos en casa e, incluso, prohibiendo utilizar tanto la palabra 'huevo' como todas las palabras derivadas de la misma raíz. Esta es la situación que lleva al pueblo a la revolución final de la obra, narrada por una reportera para un canal privado de internet, e impulsada ¡desde una carta oficial de las gallinas del hipotético país! Como podemos observar, es a través del absurdo y lo extravagante como Gama Valle se acerca a los delirios de grandeza de un dictador en el poder. No se cita a Trump directamente, pero sí se muestra en la obra una imagen calcada a muchas de las líneas de crítica que se han establecido hacia la gestión del presidente estadounidense. Así, nos encontramos al gobernante en el poder, El Presi, preocupado por publicar compulsivamente sus pensamientos más espontáneos en Twitter, como fórmula populista de comunicación inmediata con los votantes ${ }^{7}$. Por otro lado, El Presi es consciente de que si ha llegado al gobierno ha sido gracias a su popularidad en internet, que fue exactamente la estrategia del candidato Trump. El Presi alberga, además, otro de los aspectos críticos más achacados al presidente: su soberbia ${ }^{8}$. Es sintomático que incluya el autor en la obra, como una de las palabras utilizadas por El Presi, un neologismo como "grannacionense", referido a la idea de "gran nación", que sin duda alguna se relaciona con el MAGA de la campaña, pues como destacábamos al principio, si por algo ha apostado desde un principio su mensaje político, ha sido por apelar al sentimiento nacionalista de los ciudadanos. Al igual que en cualquier tipo de nacionalismo, nos encontramos también en el de este personaje un matiz excluyente para con el inmigrante de clase social desfavorecida, de manera que al racismo, se suma el clasismo ${ }^{9}$. Un último elemento a comentar, sería el que se genera acerca de otra de las ideas por las que más se ha criticado a Trump en los medios de comunicación, como es la elección a dedo de sus colaboradores ${ }^{10}$. La crítica ácida hace su aparición a lo largo de todo el texto a través de dos ingredientes como son la sátira y el humor, creando una especie de grotesco político desde el que se mira la realidad y el efecto de la actual administración. De ahí que el autor haya huido precisamente del realismo dramático con el fin de centrarse en el absurdo que conlleva implementar ciertas estrategias políticas, muy similares, como hemos venido analizando, a las del actual presidente de los Estados Unidos.

\subsection{Golpes de agua 2. Temporada de huracanes: todavía quedan restos de humedad}

Charla-performance de la autora puertorriqueña Eva Cristina Vásquez ${ }^{11}$. La exhibición tuvo una duración de diez minutos y, lo primero que destacaba la dramaturga en el paréntesis previo a su exposición, era que lo que se disponía a presentar no era teatro, sino un testimonio de lo que ocurrió en Puerto Rico antes y después del paso del huracán María. La performance consistía en la presentación, en efecto, de testimonios a través de conversaciones de WhatsApp con familiares y amigos de la isla durante aquellos días ${ }^{12}$, que suponen una fotografía fija de sus emociones. Eva Cristina Vásquez atraviesa en su acercamiento todo tipo de impresiones que una sociedad puede experimentar ante un desastre de tal magnitud. De este modo se observan risa, llanto, amargura, esperanza, solidaridad, enfado, ironía, miedo... que la autora va intercalando para crear el

El Presi: ¡Lo tengo! Podemos componer un estribillo contra los (gesticula para dar a entender "huevos") y luego difundirlo por las redes sociales, ponerlo disponible para download en una página de internet y una aplicación. Eso es lo que necesito; una campaña contra los... ya usted sabe [...] ¡Voy a twitear mi idea! [...] Es una idea radical y moderna. Esta nueva campaña me conectaría con el mundo y con las generaciones cibernéticas del pueblo y de mi pueblo. ¡Me haría un presidente cool! (Valle, 2018).

${ }^{8}$ El Presi: Cierto. Queda muy claro que yo soy el presidente con el mejor acento grannacionense en la historia de este país. En mi mandato lo he demostrado. Seis meses de claridad verbal. De gran oratoria y retórica. De hacer a los de este país sentirse orgullosos de ser de este país. Nada mal para una sensación del internet (Valle, 2018).

${ }^{9}$ Es curioso, en este sentido, uno de los comentarios que hace El Presi cuando se siente amenazado y tiene que pedir una guardia en la que depositar su confianza para su defensa personal:

El Presi: [...] ¡Llamen al FBI, a la CIA, a, a, a, a... la policía estatal. ¡No, a la policía estatal no, puede haber infiltrados en ella! ¡No empujen más! Solo llamen al FBI y a la CIA. Quiero que toda La Casa Presidencial esté protegida. Rodeada. No quiero ni gordos, ni bigotudos velando las puertas. Lo que quiero son hombres altos, fornidos y blancos con ojos azules (Valle, 2018).

${ }^{10}$ Quizás los casos más flagrantes al respecto hayan sido los de su yerno, Jared Kushner; o el nombramiento de Brett Kavanaugh como juez para la corte suprema. A este respecto, nos encontramos con el siguiente parlamento:

Guarde: ¿Qué pasaría si algún miembro de su gabinete decidiera denunciar que no fui contratado bajo el escrutinio gubernamental necesario? El Presi: ¿Un miembro de mi gabinete? (ríe desesperadamente) ¿Tú crees que alguien de mi gabinete va a denunciar algo? (Valle, 2018).

${ }^{11}$ Se estrenó por primera vez en el Instituto Cervantes de Nueva York, dentro del evento organizado por el profesor y poeta Carlos Aguasaco, titulado "Escritura e identidad. Tres escritoras latinoamericanas residentes en Nueva York", el día 23 de enero de 2018. Junto a la dramaturga, intervinieron la poeta dominicana Yrene Santos y la narradora colombiana Carolina Chaves O'Flynn.

${ }^{12}$ El intervalo de dichas conversaciones se produce entre el 6 de septiembre de 2017, cuando tocó levemente la isla el huracán Irma, pasando por el 10 de septiembre, cuando el huracán José amenaza con llegar pero finalmente no llega, y el 20 de septiembre, cuando estalla la tragedia definitiva con el huracán María. 
ritmo dramático de un momento determinado y de toda la sociedad puertorriqueña ${ }^{13}$. Como elemento fijo y siempre presente permanece la idea de incomunicación que se produjo a partir de la llegada del huracán. Esto explica un sentimiento que surgió entre muchos de los familiares que veían con impotencia cómo no podían hacer nada, después de que se hubieran suspendido, además, los vuelos y cualquier conexión con la isla ${ }^{14}$. En esta obra no se cita explícitamente a Donald Trump o a la administración de gobierno, aunque sí entiendo que la performance surge de la reflexión de la autora después de haber visto todo el trato que el gobierno dio a la isla durante y después de aquellos días, y que tantas críticas le trajo y le sigue trayendo ${ }^{15}$.

\subsection{Lo que nos dejó el huracán}

Proyecto conjunto de obras breves escritas por cuatro jóvenes dramaturgos puertorriqueños: Alejandra Ramos Riera, con la obra titulada Entre-Nudos; Ian Robles, con el monólogo titulado La linda manita; Omar Vélez Meléndez, con la obra Does your family have power?; y Kevin Delgado, con el monólogo 134 días con 47 minutos $^{16}$. Una de las constantes que llama la atención en todas ellas es el tema de la falta de luz. La luz es considerada a un mismo tiempo como un elemento de civilización y, como sucede en la obra La linda manita, un elemento incluso necesario para la cordura. En esta obra nos aparece una madre en medio de un paisaje de escombros (de la que probablemente fuera su casa), manteniendo un monólogo dialogado con tres bebés que al final se muestra que son inexistentes, fruto exclusivamente del momento mínimo de llegada de luz durante la tiniebla generalizada a la que tanto teme el personaje. Especialmente interesante es el juego con el doble significado de la palabra "power", que se realiza en Does your family have power? El personaje protagonista se cuestiona acerca de dicho significado, tanto en el sentido de "energía", "luz", como en el sentido de "poder". Esa falta de energía se relaciona directamente con la falta de poder de la sociedad puertorriqueña para reconocerse como nación y como país al margen de los Estados Unidos o de cualquier otra colonización. Dicha energía, dicho poder, se despliega a través del sentimiento de solidaridad de los ciudadanos para con sus vecinos mismos, tal y como nos describe el personaje de Toño en el diálogo con una periodista que sucede en la obra Entre-nudos, en la cual se nos relata en primera persona la experiencia trágica ante el huracán y el desentendimiento de la situación por parte de todo un gobierno. El tiempo se convierte entonces en el elemento detonante de la reacción, como ocurre en 134 días con 47 minutos, donde cada segundo de más que pasa sin que el gobierno reaccione y, sobre todo, comience a decir la verdad acerca de la tragedia que ha ocurrido (especialmente con el número de muertos), vuelca la indignación ciudadana en un discurso cada vez más crítico y vehemente, cargado de ironía... y casi a ritmo de rap. Cada una de las cuatro obras presentadas abordaba una circunstancia determinada desde un punto de vista muy biográfico en el que los autores reflejan de una manera realista (e incluso hiperrealista) sus recuerdos y emociones acerca del día en que sucedió la tragedia.

\subsection{Literal}

Drama político de la puertorriqueña Tere Martínez. Pertenece a un proyecto educativo que la autora está llevando a cabo en Puerto Rico, adonde consideró que debía volver desde Nueva York para concienciar a los alumnos desde la pedagogía teatral acerca de la identidad puertorriqueña y contra la política devastadora que Trump está llevando en materia de inmigración, intentando impulsar una serie de valores positivos que parten de la idea del reconocimiento de la problemática del otro desde un punto de vista empático y solidario. El proyecto de la obra Literal, escrito por la autora puertorriqueña dentro de un programa denominado

${ }^{13}$ De entre los testimonios más crudos, se puede entresacar este fragmento de las 9:44 am del día 27 de septiembre: “Qué dolor tan hijoeputa. Hoy todo el mundo está en silencio. Un silencio que me agudiza el pánico" (Vásquez, 2018).

${ }^{14}$ Eva Cristina Vásquez extrae uno de los mensajes enviados por ella misma que expone con claridad esta idea: "Yo nunca he sentido tanto dolor, pánico, incertidumbre, impotencia y culpa" (Vazquez, 2018). Y quizás sea esta sensación de impotencia vivida angustiosamente durante aquellos días, la que acaba llevando a la autora a cerrar la performance con el siguiente comentario: "Mi nombre es Eva Cristina Vásquez. Tengo 51 años. Nací y me crié en Río Piedras, Puerto Rico. Llevo casi 30 años viviendo en Nueva York. La madrugada del 20 septiembre de 2017 me quedé profundamente dormida en contra de mi voluntad, que quería acompañar a mi familia, a pesar de la distancia, durante el paso del huracán María. Cuando me desperté, Puerto Rico había desaparecido del mapa. Sentí a la vez tremendo vacío en el estómago y ganas de vomitar; sentí un silencio desolador y aniquilador. Dentro de ese silencio me sentí más puertorriqueña que nunca. Y cito de una pared del pueblo de Río Piedras: "quiero estar a tu laíto cuando este país reviente. A tu laíto"”, (Vásquez, 2018).

${ }^{15}$ Durante el coloquio posterior, sí hay un momento en el que la autora se refiere de manera irónica al momento en el que Trump arrojó los famosos rollos de papel toalla con displicencia a personas que lo habían perdido todo.

${ }^{16}$ Se presentaron en forma de lectura dramatizada en agosto de 2018, en el Centro Cultural Latino Julia de Burgos, en el Spanish Harlem dentro de Manhattan y bajo la subvención de la Hispanic Federation. En el mismo programa de mano se podía leer lo siguiente, acerca de la finalidad de este proyecto conjunto: "Lo que nos dejó voices the victims of Hurricane Maria after passing through Puerto Rico. After the goverment presented its official death toll of 64 deaths, due to the natural phenomenon, several investigations were unleased and proved what everybody knew: María caused thousands of deaths. We want to honor our deceased, we want to have a number, we want to know their names". 
"Raíces y acción: construyendo identidad", sitúa la acción, sin embargo, en un tiempo presente y directamente relacionado con la devastación del huracán María en su paso por Puerto Rico. Se parte, en principio, de una situación ajena a la reflexión política (como es la de un viaje en avión de dos adolescentes desde EE.UU. hacia San Juan de Puerto Rico), para, a partir de ahí, desembocar en un diálogo acerca del futuro y de los deseos frustrados que se relacionan no solo con la administración actual, sino con todas las administraciones anteriores, si bien lo interesante es que es ahora, después de la gestión de la administración Trump acerca de la tragedia del huracán María, cuando la puertorriqueña ha sentido la necesidad de hablar más políticamente que nunca, intentando concienciar a través de la educación. Nos encontramos ante dos personajes jóvenes (Él y Ella) que van a experimentar todo un proceso de autoconocimiento identitario que parte, como aludíamos anteriormente — e insisto en destacar por su significado_-, del desastre ocurrido ante la llegada del huracán María. Ambos personajes viven fuera de Puerto Rico, pero ninguno de los dos sabe muy bien dónde se encuentra realmente, porque han salido (Ella deseando marcharse y Él por obligación) de su tierra. De manera que ambos tienen la sensación de estar situados en una especie de limbo o tierra a la que no pertenecen ${ }^{17}$. La idea que se desprende es la de que todo puertorriqueño fuera de su tierra está, en definitiva, perdido, porque no es capaz de hallar su identidad. De manera muy explícita el personaje Él relata su sensación de extrañeza en el sistema educativo de los Estados Unidos ${ }^{18}$. Ella, sin embargo, se muestra menos nostálgica con su tierra de origen. Incluso llega a pronunciarse de manera despectiva, adquiriendo un tono sarcástico ante la idea emocional del chico de haber interiorizado la esencia de su país ("llevo un país propio por dentro") ${ }^{19}$. La búsqueda infructuosa de Ella por integrarse en el sistema norteamericano y olvidarse definitivamente de su país se ve sacudida por el huracán María. Ahí es donde Ella se percata de que su verdadera identidad no estará jamás completa fuera de Puerto Rico. De modo que es en este viaje de regreso donde Ella y Él se atreven a manifestar lo que nunca habían enunciado en voz alta y llevaban reprimido muy dentro. El viaje en avión durante el cual se ambienta la obra es una metáfora del Mito de la Caverna platónico, construido en torno a la transición difícil por la que pasa todo puertorriqueño hasta comprender cómo articular la propia idea de sí y de su identidad, a partir de: las herencias culturales (aborígenes e hispanas); las circunstancias políticas impuestas (estadounidenses); y el propio yo. El avión sufre una serie de diferentes contratiempos a causa de una tormenta, que le obligan casi a retornar a los EE.UU. Después de hacer una parada en un aeropuerto todavía estadounidense, se anuncia que reanudarán el vuelo rumbo a Puerto Rico. En esa puerta de embarque del aeropuerto estadounidense, los personajes de Él y Ella ya son otros, ya han comenzado a conocer su identidad y, desde ahí, sentirse orgullosos de sí mismos, de modo que la llegada a la isla ahora se convierte en un ferviente deseo ${ }^{20}$. Ella representa la crítica hacia Puerto Rico y la idea de que "todo lo americano es mejor" (Martínez, 2018), tal y como Él nos explica que dice su madre. Él representa la emocionalidad sin planteamiento crítico alguno, el amor completamente irracional

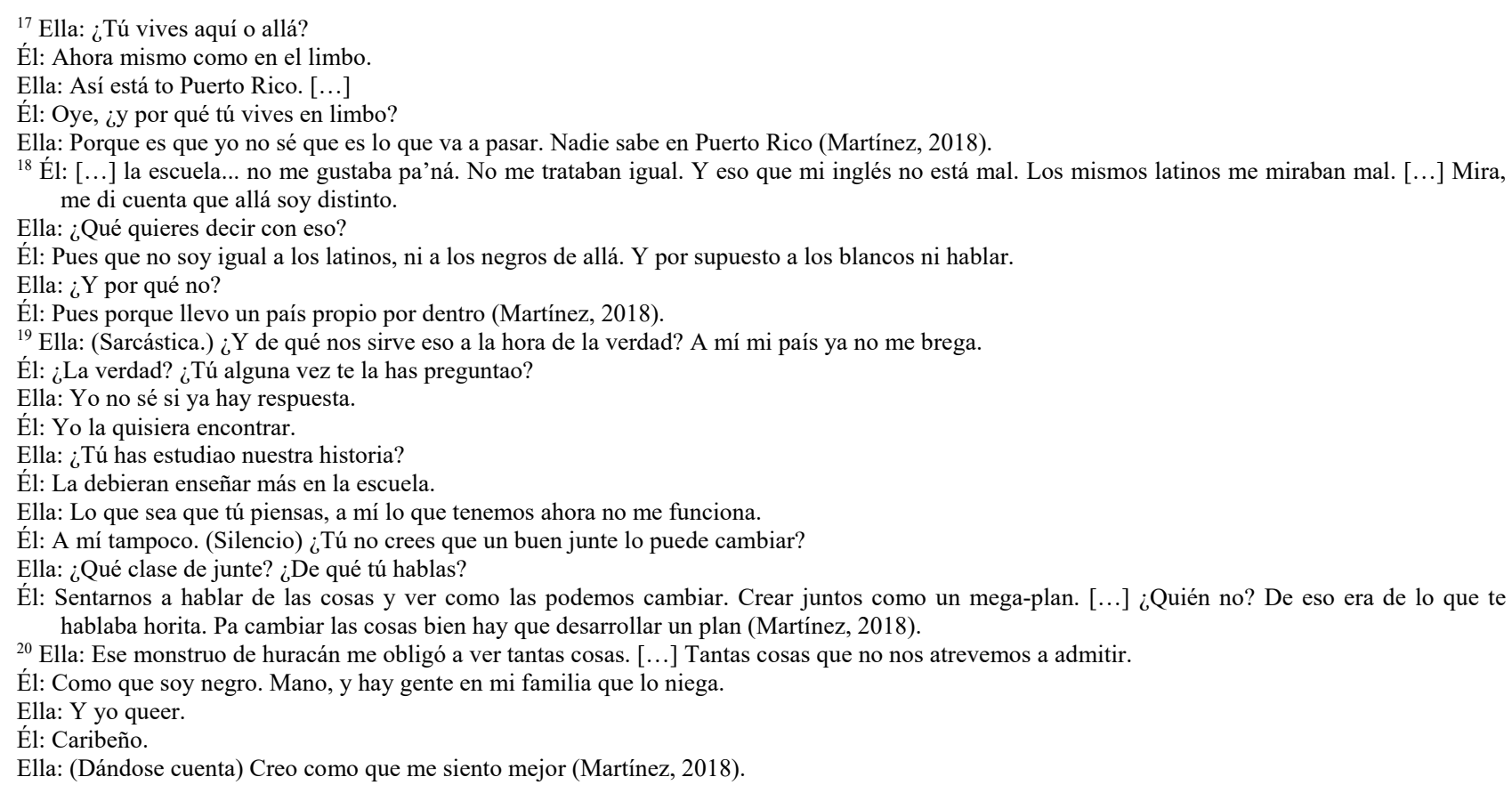


por la tierra y sus gentes. Juntos, la crítica y el amor, pueden construir un plan nuevo de identidad, una identidad con valores y no solo con emociones, una identidad que luche por existir desde la racionalidad y la inteligencia y no exclusivamente desde el instinto, de manera que ese nuevo latido identitario genere una construcción mucho más sólida y avanzada de la realidad de Puerto Rico. Cada uno de los chicos se aportan lo que le falta al otro. Él quiere estudiar neurociencia, que representa el aspecto inmaterial o esencial de la identidad; Ella, arquitectura, es decir, el aspecto material, estético... la imagen y la forma de esa identidad. De manera que ese "mega-plan" (Martínez, 2018) del que se habla significa, en definitiva, la unión solidaria para tener un futuro mejor dentro de la isla ${ }^{21}$.

\subsection{Cada vagón es un mundo}

Pieza breve del autor dominicano Alex Vásquez Escaño, inserta dentro de un libro de autoría conjunta con el resto de los integrantes del grupo Teátrica de Nueva York (Morón, 2015), titulado Una ciudad: cuatro estaciones, cuya publicación está planeada para mediados de 2019. En una de mis entrevistas con el autor pude conocer que la obra aludida fue escrita en 2011, si bien la coyuntura del actual momento político es lo que le llevó a publicarla en este año. La acción sucede en un vagón de metro neoyorquino, con dirección al barrio de Queens (popular barrio obrero) en el que coinciden varios personajes anónimos e intercambian unos minutos de conversación. El instante que más nos interesa para esta investigación es la entrada en escena de un personaje llamado Donaldo Tramposo, y, sobre todo, nos interesa el retrato que de este personaje realiza el autor. Donaldo Tramposo se nos muestra como uno de los miembros de una mafia que utiliza la caridad hacia la gente sin hogar para lucrarse ellos mismos. El personaje entra con un carro ofreciendo agua y un sándwich solo a quien lo necesite; y, a quien no lo necesite, le pide que entregue un dólar para contribuir con una - falsa - fundación de ayuda a los homeless. Pero Donaldo se topa con Rodolfo, un obrero que conoce y domina la situación, articulando un juego para demostrar el fraude ${ }^{22}$. La paronomasia fonética generada entre el nombre propio del presidente y un adjetivo como "tramposo" es un signo más que evidente de la visión que el autor de esta obra está sugiriendo acerca Trump: alguien que ha llegado al poder a través del engaño. No podemos concluir, sin embargo, que exista en esta obra una cita directa con nombre propio, aunque, como se puede apreciar, la sugerencia es incuestionable. El texto pone énfasis en destacar la imagen de Donaldo Tramposo como un pícaro que está dispuesto a hacer cualquier cosa para lucrarse $\mathrm{e}^{23}$.

\subsection{Queens of the night}

Drama musical del autor y actor de origen español y residente en Nueva York desde hace varios años, Txemi Parra. La pieza se ambienta entre los camerinos y el escenario mismo de un teatro, en el que un grupo de

\footnotetext{
${ }^{21}$ Él: ¿En serio, loca? Acho, qué riverzaso’ tú has dao’! (Se toman un selfie) Aquí empieza un nuevo junte.

Ella: ¿Pá' crear el mega plan?

Él: Por un nuevo Puerto Rico.

Ella: Donde se escuche mi voz.

Él: Y podamos ser parte de la solución. [...] Quiero estar en Puerto Rico y tratar de entender ¿por qué Mami piensa como piensa? ¿Por qué en vez de juntarnos cada día nos separamos más? ¿Por qué tenemos tanto miedo a ser dueños de nosotros mismos? (Martínez, 2018).

${ }^{22}$ Donaldo: Ladies and gentlemen, damas y caballeros: Buenos días me llamo Donaldo Tramposo y trabajo para la Asociación de Desamparados sin Ayuda...Si alguien en este vagón tiene hambre, no se ha bañado, tiene mal aliento y le huelen los pies...puede tomar unos de estos "sándwich" que hemos preparado con donaciones que personas como ustedes nos han dado. (Rodolfo se levanta)

Rodolfo: Fraude...Mi amigo...Por favor. (Levantando la mano. Manuela le da una pequeña donación)

Donaldo: (A Manuela) Qué generosa es usted. (Se va donde Rodolfo) ¿También quiere ayudar?

Rodolfo: No. Quiero uno de esos sándwich.

Donaldo: Pero como que usted no lo necesita.

Rodolfo: Un desamparado no tiene cara.

Donaldo: No como la que tiene usted.

Rodolfo: ¿Qué quiere usted decir con eso? (Dándole un Sandwich)

Donaldo: ¡Así, gorda y colorá!

Rodolfo: Gracias muy amable. (Comiéndose el sándwich)

Donaldo: ¿No va contribuir con algo?

Rodolfo: ¿Usted lo está vendiendo?

Donaldo: No.

Rodolfo: Pues no me lo cobre...

Donaldo: No le estoy cobrando... Solo que le pido una ayudadita.

Rodolfo: ¿Y quién me va ayudar a mí?...

Donaldo: ¿Para los desamparados usted no tiene?

Rodolfo: Para ellos sí. Para usted es que no tengo (Vásquez Escaño, 2018).

${ }^{23}$ No hay que olvidar que el presidente Trump ha estado envuelto a lo largo de su vida en numerosos escándalos de negocios fraudulentos. Uno de los más sonados fue el que perpetró en el año 2005, creando una Universidad Trump que resultó ser una estafa.
} 
Drag Queens trabajan cada día por y para el espectáculo de un pequeño teatro en Queens ${ }^{24}$. La obra está construida a modo de cabaret, con un aporte ingente de números musicales, entre los que se intercalan diferentes diálogos de corte realista, a través de los cuales podemos observar cómo los personajes van sacando a la luz sus dramas personales, sus preocupaciones o sus sueños. Esta es una de las obras con un carácter más marcadamente político, en la que se cita al presidente Trump de manera directa y clara, desde un punto de vista jocoso e irónico, cargado de complicidad entre los propios personajes; y no solo eso, sino también cargado de complicidad con el público. Pero la verdadera crítica a Trump y a su gobierno viene especialmente protagonizada a través de la figura del personaje de Mike, un compositor y mentor de uno de los intérpretes del show. Mike representa al ciudadano con conciencia política que no tiene problema alguno en verbalizar lo que quizás todos piensan, pero que a todos molesta sacar a la luz, porque les obligaría a comprometerse; así aparece por primera vez dentro del drama para ofrecer la interpretación durante la representación de esa noche de un número musical cargado de sentido político: "A Trumpazos" 25 . Mike denuncia cómo la falta de compromiso, el seguir mirando para otro lado, la incapacidad de asociación y la inacción de algunos ciudadanos —en gran medida muy afectados por la actual administración Trump - ha conducido a una situación de injusticia que durará hasta que esos ciudadanos no se alíen para cambiarla ${ }^{26}$. Pero, ante la falta de apoyo, lo único que le queda es desahogar su propia frustración en soledad, a través de unos ejercicios bastante sui generis para templar la voz en escena ${ }^{27}$. La voz de Mike simboliza la voluntad de hacer un llamamiento a la ciudadanía para luchar ideológicamente contra la amenaza y la ansiedad que suponen las políticas represivas de la actual administración de gobierno en ciertos sectores de la sociedad neoyorquina, concretamente la referida a inmigrantes, homosexuales y transgénero. La obra se convierte, pues, en una de las más ricas temáticamente de entre las creadas hasta el momento, dado que, como vemos, es completamente transversal y constituye un pequeño microuniverso de lo que está pasando en el teatro hispano de Nueva York.

\subsection{Trans-Mission}

Monólogo de la performer neoyorquina y puertorriqueña Barbra Herr ${ }^{28}$. Nos encontramos dentro de este texto ante el género dramático de la autoficción, en la que la autora y actriz cuenta la historia de su vida, girando el foco de atención principal del argumento en torno a las dificultades y obstáculos que conlleva la reasignación de sexo. Barbra Herr nos acerca al mundo de las consultas psiquiátricas y a todos los estigmas que la sociedad genera en este colectivo. Las garantías de que una mujer trans pueda desarrollar plenamente su personalidad dependen en gran medida del desarrollo tanto de la medicina como de los programas de salud. En este sentido la autora relata cómo "Gracias al Presidente Obama y al Gobernador Cuomo de New York, una nueva legislación fue aprobada permitiéndole a las personas trans equidad bajo la ley" (Herr, 2017), lo que implicaba una especial sensibilidad a través de la cual "todo cuidado médico para personas trans, incluyendo cirugías necesarias para el bienestar mental y emocional de esta comunidad son obligadas a

${ }^{24}$ Esta obra fue estrenada en 2018 en el Teatro Thalía, dirigida por Ángel Gil Orrios, productor ejecutivo también de dicho teatro, con lo cual se hace patente una cercanía entre la propia historia del drama y las circunstancias reales del espectáculo mismo.

${ }^{25}$ Mike: Es una ranchera sobre los inmigrantes. In this country we are all inmigrants, ¿right? It's a perfect cocktail with everything in it. The number is called "ATrumpazos". Just let us show it to you (Parra, 2018).

${ }^{26}$ JP: Lo de esta mina es increíble, lo que chillaste y ahí la tenés, frita...

Mike: No sé cómo puede dormir.

JP: Obviamente está tomada.

Mike: I don't give a dam about her! What matters is that an innocent person was beaten up for being gay and Latino. And you know what's worst? That nothing happens to those savages. They are not gonna be caught, and if they do, they'll enter one door and exit another. Este es el GRAN país ese pendejo levanta-muros is building! That's his sick way of making América GREAT again.

JP: Poco podemos hacer.

Mike: You're wrong, podemos hacer y mucho, YES WE CAN! We have to go out to the streets and protest. We can't just sit back and do nothing. Ahora mismo tendríamos que buscar a esos cabrones y darles su merecido.

JP: Ya, pero estamos trabajando, we are artists. Por cierto, I'm gonna talk to the boss so he can let me replace Ángel, y hacer el número final. Mike: i¿What?! ¿Cómo puedes ser tan egoísta? [...] You're sick! [...]

JP: You are the one who's sick! Te pasas el día hablando de política, complaining against Trump, that's the only thing that matters to you. En realidad Ángel te da igual, sólo es una excusa para poder seguir criticando (Parra, 2018)

${ }^{27}$ Mike: (Hace ejercicios de voz) Ahhhhhhhh... Buah, buah... Rrrrr... Relax your body. (Hace ejercicios de relajación) Get rid of the stress. (Mueve y golpea con los brazos al aire) Suppose you have in front of you Trump... Come on, hit, hit hard, and now kick him on his ass, yes, guey, for asshole. (Da patadas al aire.) Por pendejo. Es muy importante calentar el cuerpo bien (Parra, 2018).

${ }^{28}$ Fue estrenada en Teatro Círculo, en el año 2017, en inglés. Posteriormente, en el año 2018, se realizó una lectura en español en la librería hispana de Queens, Barco de Papel. Y sabemos que la autora pretendía haber estrenado el texto también en Puerto Rico, pero la tragedia del huracán María la obligó a posponerlo. 
ser cubiertas por todos los seguros. Incluyendo Medicaid" (Herr, 2017). A partir de aquí la performer se pregunta si existe la posibilidad de que "este privilegio desaparezca bajo esta nueva administración presidencial". Y así, la última parte del monólogo se constituye en toda una llamada a la sensibilización por parte de la administración política, a la que se le pide exclusivamente justicia, igualdad y respeto ${ }^{29}$. La aparición de personajes trans en las obras hispanas actuales de Nueva York posee así un efecto reivindicativo de todo cuanto este colectivo ha sufrido para poder obtener una identidad social al margen de la fobia y la violencia de muchos sectores de la sociedad misma ${ }^{30}$.

\subsection{Busca-la-vida}

Tragedia en un acto del dramaturgo venezolano Pablo García Gámez. Fue escrita en noviembre de 2018 y considero que es muy importante tener presente la fecha en la que sucede el proceso de escritura, por todo lo que en el momento actual estaba pasando, en referencia a la "caravana de migrantes" de cinco mil personas procedentes de diferentes países de Centroamérica como Honduras, El Salvador, Guatemala y Nicaragua, con destino a la frontera entre Méjico y EE.UU. La obra establece una diferencia fundamental entre los personajes con rostro humano, aquellos que son busca-la-vida, frente a personajes sin rostro humano: dos voces en off diferentes, una de un juez de la "Corte judicial para casos de inmigración y centro de detención anónima para niños"; y otra que el autor denomina "Voz en off impersonal", que, en definitiva, es un remedo del Estado mismo, que actúa dentro del "Centro de detención de adultos, de los que se esconden en la frontera México-Estados Unidos". Ambos centros están concebidos como una especie de "limbo" en el que los personajes con rostro humano esperan la decisión acerca de sus vidas y su futuro. Pablo García Gámez nos sitúa ante dos espacios diferentes y dos acciones de carácter paralelo con un mismo fin. Por un lado asistiremos al interrogatorio despiadado de un niño que ha sido separado de su madre en el momento de pedir asilo. Marino, el niño, no sabe hablar inglés, idioma en el que el juez lo interroga, de manera que se muestra completamente indefenso ante la situación, no solo por su corta edad, sino también por el desconocimiento de una lengua concreta, que le impide sencillamente expresar ${ }^{31}$. El juicio al niño está presentado en la obra a través de distintos fragmentos que se van introduciendo en momentos puntuales, con lo cual se crea una eficacia dramatúrgica máxima de suspense, y, además, se genera una sensación creciente de atmósferas paralelas, que lleva a sugerir una connivencia entre poder político y judicial para deshacerse de los inmigrantes ${ }^{32}$. Por otro lado, en la acción situada dentro del centro para adultos, nos encontramos con tres personajes pidiendo asilo político, que representan tres universos diferentes y arquetípicos de la inmigración: Eusebia, madre de Marino, que decidió salir de su país el día en que a su marido"Lo apuñalaron, le cortaron

${ }^{29}$ Barbra Herr: Pero, por favor, tengan en cuenta que no pueden crear leyes con fin de silenciarme sencillamente porque usted me reconoce como alguien fuera de lo normal. No me pueden negar entrada a sus escuelas, a sus baños, a edificios, a sus urnas o a ningún lugar simplemente por ser quien yo soy (Herr, 2017).

${ }^{30}$ El colectivo trans (y muy especialmente la parte del colectivo de origen latino) ha sido especialmente reivindicativo de sus derechos, al sentir cómo desde la actual administración se les está tratando de invisibilizar.

${ }^{31}$ Durante el interrogatorio, conocemos que al juez le ha llegado una información mezclada en el expediente, por la que se dice que el niño es de Guatemala; al escuchar el nombre de ese país, el niño responde diciendo "Honduras", pero el juez no lo escucha y sigue el dictado del expediente, con lo cual, al final, sabremos que al niño lo deportan a un país que no es el suyo, dejando en suspenso para el lector-espectador —aunque claramente sugerido - cuál será el destino de ese niño; y sobre todo dejando claro cómo el Estado, a través de la figura del poder judicial, solo busca deshacerse cuanto antes del problema.

${ }^{32} \mathrm{Voz}$ en off juez: Order in the court! These are removal proceedings in the matter of Marino Robles [...] The respondent is not represented by an attorney... [...] Do you want this hearing conducted in Spanish?

Marino: ...

Voz en off juez: This court cannot afford a translator for the defendant [...] The government charges you with being a native and citizen of Guatemala...

Marino: Honduras.

Voz en off juez: The documents state you are from Guatemala [...] ....and that you are presently in the United States without legal permission or parole.

Marino: ...

Voz en off juez: Have you talked to an immigration attorney?

Marino: ...

Voz en off impersonal: Do you have an attorney?

Marino: ..

Voz en off juez: Do you know what a lawyer is?

Marino:...

Voz en off juez: This court rules that your asylum petition won't be granted. You will be deported immediately to your native country, Guatemala.

Marino: ¡Honduras!

Voz en off juez: I said Guatemala, your native country.

Marino: ¡No! ¡Mamá...! (García Gámez, 2018). 
la lengua, le arrancaron los ojos. Dejaron el cadáver en el camino como advertencia... mi hijo vio a su padre así". (García Gámez, 2018) ${ }^{33}$; Sula - nombre extraído de la ciudad de San Pedro de Sula, desde donde partió la caravana de migrantes hondureños hacia Estados Unidos-, cuyo hijo partió en "La Bestia"34 y que ya se había visto obligado a realizar una inmigración interna dentro de su propio país, Honduras, debido a las extorsiones de las mafias ${ }^{35}$; $\mathrm{Y}$, en tercer lugar, tenemos a Gloria, una mujer trans que viene de sufrir un grado máximo de acoso y rechazo en su país ${ }^{36}$. Como podemos observar, el autor trae a la realidad del espectador la historia de vida de tres personas procedentes de realidades peligrosas. Lo que pretende el autor así es humanizar la imagen del busca-la-vida, haciendo que los espectadores puedan identificarse con una realidad de la que quizás están muy alejados. Uno de los principales hallazgos de la obra de García Gámez es precisamente su procedimiento dramatúrgico establecido desde una interpelación brechtiana del espectador; este procedimiento lo introduce en la problemática de las circunstancias de manera que se disuelve la frontera entre la ficción de lo representado y la realidad de quien observa. Frente a los personajes con rostro humano, la Voz en off impersonal va repitiendo códigos que corresponden con expedientes de seres humanos. Es como si lo que no está deshumanizado tuviera la capacidad de decidir acerca de los destinos de los seres humanos. Se potencia además el choque violento a través de la incomunicación que se genera debido a un lenguaje no compartido, como observábamos que ocurría en la línea argumental del juicio a Marino $^{37}$. Y, por supuesto, también aparece como deshumanizada, tratándolo como fantoche grotesco, la imagen de Donald Trump, a quien ni siquiera se le cita por su nombre, sino desde la ridiculización de su aspecto y su discurso ${ }^{38}$. Por otro lado, Pablo García Gámez introduce un elemento interesante de perspectiva sociopolítica y que quizás esté tomando un nuevo auge en la era Trump. Me estoy refiriendo al miedo a ser tachado de comunista, algo que parecería en un principio más relacionado con la sociedad estadounidense de la caza de brujas durante el macartismo, que con el mundo actual. Sin embargo, aquí se nos muestra cómo el personaje de Sula (que en ningún momento lanza un discurso declaradamente comunista) es rehuído por parte de Eusebia (en un principio, si bien luego se adhiere a él) y de Gloria, quienes, mirando al público, aclaran que no tienen nada que ver con el comunismo. En definitiva, de lo que nos está hablando el autor es de la falta de libertad de expresión que se está comenzando a producir en los sectores más vulnerables de la sociedad estadounidense, ante las amenazas continuas del presidente y el miedo perenne en los inmigrantes a ser deportados por alguna causa que incluso pueda escapar a su control (fruto de la desconfianza en ellos mismos como consecuencia del desconocimiento del idioma ${ }^{39}$. Pablo García Gámez ha apostado por situar el derecho a la vida y a un futuro mejor como el elemento esencial de cada ser humano. Es interesante destacar cómo, en su búsqueda de una universalidad desde unas circunstancias y un espacio particulares, desde el comienzo mismo del texto, al hacer referencia al tiempo en el que se desarrolla la obra, aclara el autor: "Siempre. En unos años más que en otros, con unos gobernantes más que con otros, pero siempre"

${ }^{33}$ Eusebia: Lo apuñalaron, le cortaron la lengua, le arrancaron los ojos. Dejaron el cadáver en el camino como advertencia... mi hijo vio a su padre así (García Gámez, 2018)

34 Tren que introduce a los inmigrantes de manera ilegal en los EE.UU.

${ }^{35}$ Sula: mi familia tenía una finquita de café... daba para vivir. Llegaron un día; amenazas: si no nos íbamos nos mataban [...] Tenían amigos en el gobierno. No hice caso. Una semana después mi esposa apareció muerta (García Gámez, 2018)

${ }^{36}$ Gloria: De donde vengo, la violencia nos arrulla. Nos insultan, nos roban, nos agreden. Aparecemos muertas, torturadas, calcinadas. La policía también nos chinga... también nos mata porque somos jotos... jotas. Dime si no cumplo con los requisitos (García Gámez, 2018)

${ }^{37}$ Voz en off impersonal: B-251544, B-831237, B-751302, B-657822, B-151243... Your petition to get asylum has been rejected. Go to the front yard. You will be picked up by ICE agents that will escort you to your native country (García Gámez, 2018).

${ }^{38}$ Eusebia: En la televisión del centro de detención a cada rato aparece un viejo naranja encachimbado...

Sula: ¿Viejo naranja?

Eusebia: Sí. Pone cara de constreñido y dice: "vienen a robar, a matar, a robarnos los trabajos, a quedarse con lo nuestro. Son bad hombres. Mandaré militares a cuidar la frontera. Si tiran una piedra, que les disparen" (García Gámez, 2018).

39 Sula: No tiene que hablar bajito. Es sentido común. ¿No quieren vernos? Que no jodan, que no expropien, que no invadan países ni tumben gobiernos. ¿Les interesan los pueblos? Que no pongan a criminales en el poder, que no manden sus mugrientas compañías hambreadoras ni que tampoco estrangulen de hambre o de guerra a los pueblos $[\ldots]$

Eusebia: Volteen hacia allá (Se refiere al público). Esos son los que nos escuchan.

Gloria: Los veo inertes... vegetando.

Sula: ¡Qué espías ni qué nada! Llegaron antes que nosotros. Están cansados esperando su turno. ¡Espías!

Eusebia: Por si acaso. (Hacia el público). ¡No soy comunista! ¡No creo lo que dice este señor! ¡Primera vez que lo veo!

Sula: ¡No seás boba!

Gloria: ¡Yo tampoco soy comunista! ¡Si quieren devolver a alguien, que sea a él!

Eusebia: ¿Habrá cámaras?

Gloria: ¡Yo no las veo, manita!

Sula: ¡Qué falta de solidaridad!

Eusebia: No quiero tener problemas con el asilo (García Gámez, 2018). 
(García Gámez, 2018). García Gámez está haciéndose eco de la migración no como un hecho puntual, sino como un hecho antropológico, histórico e, incluso, psicológico humano, que nace de la desigualdad social, considerando la sociedad desde la perspectiva postmoderna de la aldea global, en la que, en definitiva, todos nos conocemos, de manera que para empatizar con el otro solo necesitamos un tiempo de escucha al que, como público espectador o lector, estaremos sometidos a través del propio hecho teatral.

\section{Conclusión}

Como hemos podido observar, no todas las obras comentadas tratan acerca de absolutamente todos los aspectos que aparecen planteados en las diferentes líneas temáticas que se definían en el primer punto de este artículo. Esto quiere decir que algunos de los planteamientos políticos de los distintos artífices del fenómeno del teatro hispano de Nueva York está todavía por desarrollar literariamente. Aún así, si combinamos las diferentes líneas temáticas con las obras destacadas y el tipo de cita (directa o indirecta) que aparece en las misma acerca del presidente Trump o de su administración, obtendríamos una tabla que obedecería a la siguiente estructura:

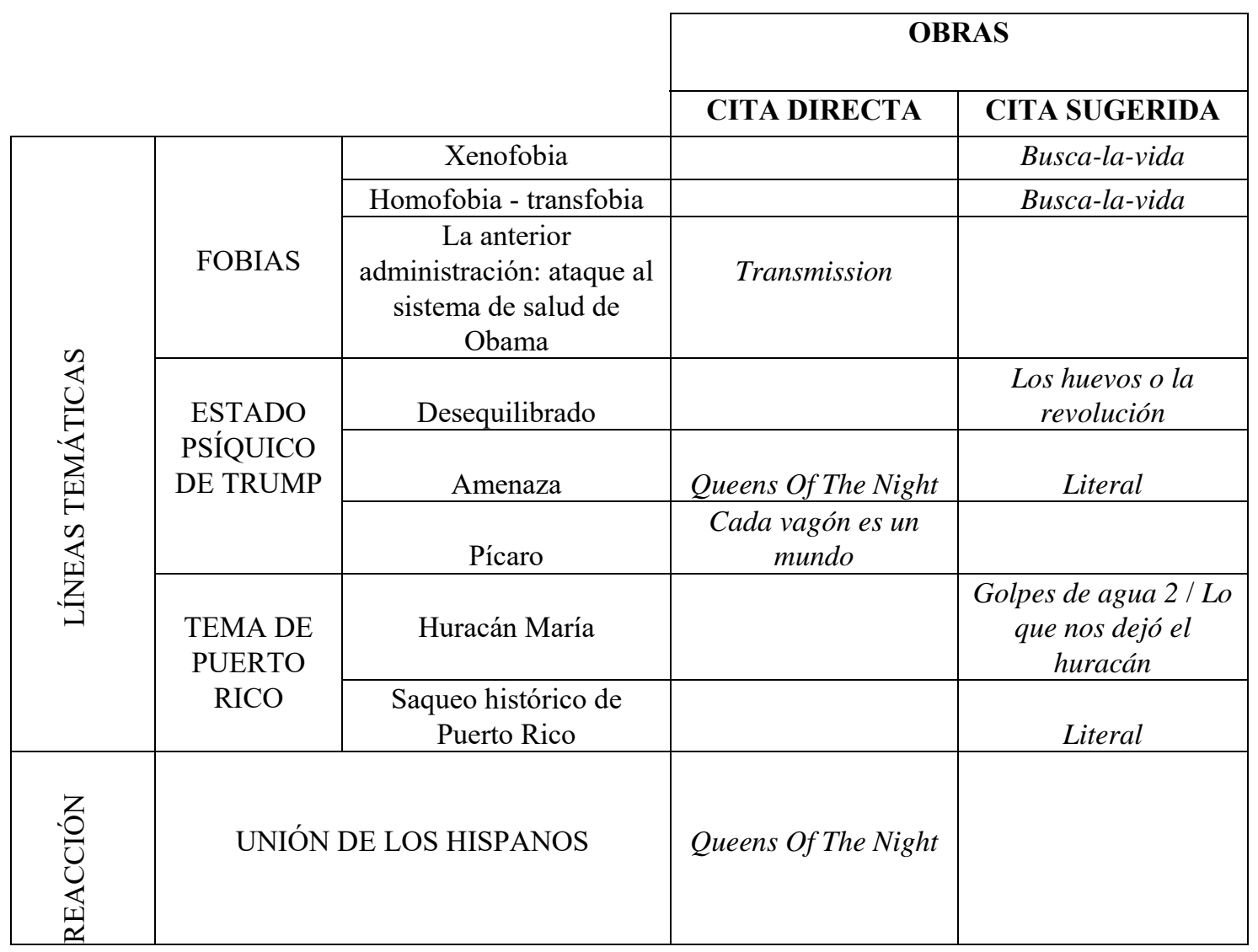

Tabla 1. Líneas temáticas, obras y tipo de cita.

Las obras aquí presentadas, en definitiva, son fruto de un choque entre diversas circunstancias que vienen unidas por una gran ciudad que alberga grupos muy diferentes, con diferentes identidades nacionales y/o de género, que a un mismo tiempo se sienten violentados a causa del discurso que emana del poder político en el momento actual. La visibilidad de estos grupos puede ser más o menos relevante para la política del Estado, pero está claro que si casi todas las obras comentadas han sido estrenadas o leídas públicamente en teatros pequeños, del off off, del margen... es porque algo está cambiando desde abajo, algo está generando un movimiento que podría llegar a producir o a contribuir con una voluntad generalizada de cambio político.

El teatro permite imaginar situaciones, circunstancias, discursos... que no han sido documentados pero que podrían ser verosímiles. La verosimilitud es, en definitiva, la garante de que la imaginación aparezca, desarrollando un análisis particular que, siguiendo postulados kantianos, estaría muy por encima del análisis 
de la realidad que se puede hacer desde otros campos. Porque la verosimilitud queda establecida, en gran medida, dentro de la esfera de lo sensible, y así, las circunstancias dadas del teatro quizás no se pueden documentar, pero pueden producir sensación de existencia. De este modo, el análisis llevado a cabo sobre la realidad política actual de EE.UU. desde la dramaturgia hispana de Nueva York, ayuda a comprender lo que está pasando desde un punto de vista emocional, frecuentemente más cercano al devenir social.

\section{Referencias bibliográficas}

Delgado, Kevin (2018). 134 días con 47 minutos. Inédita.

García Gámez, Pablo (2019). Al margen: Teatro y Comunidades Hispanas en Nueva York 1997-2011. Inédita. (2018). Busca-la-vida. Inédita.

Herr, Barbra (2017). Trans-Mission. Inédita.

Martínez, Tere (2018). Literal. Inédita.

Morón, Antonio César (2015), "El teatro escrito en español en la Ciudad de Nueva York: búsqueda y generación de identidad(es) desde la dramaturgia", Latin American Theater Review, 48-2, págs. 87-106.

Parra, Txemi (2018). Queens of the night. Inédita.

Ramos Riera, Alejandra (2018). Entrenudos. Inédita.

Robles, Ian (2018). La linda manita. Inédita.

Valle, Gama (2018). Los huevos o la revolución. Inédita.

Vásquez, Eva Cristina (2019), "Golpes de agua 2. Todavía quedan restos de humedad". Disponible en: https://m.facebook.com/story.php?story_fbid $=10155943749963954 \& \mathrm{id}=707698953$

Vásquez Escaño, Alex (2018). Cada vagón es un mundo. Inédita.

Vélez Meléndez, Omar (2018). Does your family have power? Inédita. 